\title{
Les nouveaux mécanismes du contrôle organisationnel
}

\author{
Rosimeri Carvalho da Silva ${ }^{1}$
}

\begin{abstract}
Resumo
Neste ensaio são discutidos os mecanismos de controle postos em evidência pela adoção de novas tecnologias de gestão que proporcionaram uma reestruturação produtiva. A relevância desta discussão reside na compreensão de que a adoção destas novas tecnologias provoca alterações no sistema de controle que, apesar de não substituírem completamente os modos de controle utilizados anteriormente, enfatiza um modo de controle mais sutil que privilegia mecanismos capazes de influenciar o compartilhamento de uma visão de mundo.
\end{abstract}

Palavras-chave: controle, tecnologia de gestão, restruturação produtiva

\section{Résumé}

Dans cet essai on discute les mécanismes de contrôle mis en évidence par l'adoption de nouvelles technologies de gestion qui ont proporcionné une restructuration productive. La relevance de cette discussion est dans la compréhension que l'adoption de ces nouvelles technologies impliquent des alterations dans le système de contrôle que, même si elles ne remplacent pas complètement les modes de contrôle utilisés avant, mettent l'accent sur un mode de contrôle plus subtil que privilegie des mécanismes qu'influencient le partage d'une vision de monde.

mots- clés: mécanismes de contrôle, technologies de gestion, restructuration productive

\begin{abstract}
In this essay new control mechanisms brought to new management technologies aiming a productive reestructuration are discussed. The relevance of this discussion is based on the comprehension that new technologies cause changes in the control system that, although do not substitute totally the old control mechanisms, emphasize a new and delicate mode of control able to direct a shared world vision.
\end{abstract}

Keywords: control mechanisms, management technologies, productive reestructuration

\section{Introduction}

Les changements des modes de contròle utilisés dans les organisations les derniers temps, surtout dans les deux dernières decennies du XXème siècle ont reçu beaucoup d'attention, soit de ceux directement engagés dans la gestion des organisations, cadres, executifs, consultants, soit des chercheurs dans leur effort de comprendre les transformations organisationnelles.

En effet, la reorganisation productive promue par les nouvelles technologies de gestion impliquent des transformations que semblent être un défi pour la compréhension fondée sur les anciens cadres d'analyse des théories organisationnelles. La littérature de divulgation de ces nouvelles pratiques met l'accent sur une transformation radicale qu'impliquerait une organisation nouvelle, absolument differente des organisations gerées dans les modèles anterieurs. Pour cete litérature l'autonomie, la liberté des hommes et femmes, serait plus grande que jamais dans les «nouvelles entreprises », les organisations n'ayant plus la rigidité des relations hierarchiques conséquentes de la séparation entre travail intelectuel et travail manuel. Néanmoins, les chercheurs qui ont commencé à analyser ces changements ont relativisé ses résultats, notamment sur cette proclamée liberté et ont affirmé la possibilité que les nouvelles techniques aideraient à créer un nouveau régime autoritaire de gestion.

Fondés sur ces études et l'observation de certaines organisations nous nous sommes interéssés à un aspect que nous semblait central, les mécanismes du contròle organisationnel. Les changements dans les organisations et

\footnotetext{
${ }^{1}$ Professora do CPGA/U|FSC. Doutora em Administração pela École de Hautes Études Commerciales - HEC-França. E-mailrosimeri@ cse.ufsc.br.
} 
les analyses déjà réalisées nous paraissent signaler un changement des modes de contròle utilisés par les organisations dans le sens d'un contrôle apparement bureaucratique, donc visible, vers un contrôle plus subtil et moins apparent, mis en place par un ensemble de mécanismes aindant à faire partager une vision de monde. Ce mode de controle a reçu différentes denominations, controle culturel, controle consensuel, concertive control, nous l'avons appélé, même si cette appelation ne résoud pas touts les problèmes d'interprétation, contrôle à travers la culture, dans le but de affaiblir la compréhension assez discutable de la possibilité de gérér la culture. Dans ce texte nous présentons les discussions théoriques sur les mécanismes de ce mode de contrôle en les contrastant avec les mécanismes plus traditionnels et plus connus du contrôle bureaucratique, même si l'accent est mis sur le premier.

\section{Le contrôle - une question centrale pour les études organisationnelles}

Les concepts de contrôle qu'on peut trouver dans la littérature organisationnelle sont divers et peuvent être interprétés de plusieurs façons. Anthony (1988, p. 9) envisage le contrôle comme la façon par laquelle on s'assure de l'implémentation des stratégies, mais il donne aussi un sens plus large où le contrôle « has the purpose of conforming the behavior of some person or thing to a desired state of affairs ».

Tannenbaum, l'un des plus importants théoriciens du contrôle, le définit, en 1968 :

« Organization implies control. A social organization is an ordered arrangement of individual human interactions. Control processes help circumscribe idiosyncratic behaviors and keep them conformant to the rational plan of the organization. Organizations require a certain amount of conformity as well as the integration of diverse activities. It is the function of control to bring about conformance to organizational requirements and achievements of the ultimate purposes of the organization. The coordination and order created out of the diverse interests and potentially diffuse behaviors of members is largely a function of control».

On voit par, le concept, la lutte entre l'ordre et le desordre. Lutte dans laquelle se trouvent toutes les organisations en tant que instruments de régulation. Le concept de contrôle est intimement lié à celui de pouvoir dans le sens où il présuppose l'action de quelque chose ou de quelqu'un sur le comportement, l'action ou la pensée d'une personne ou d'un groupe de personnes ou des choses. En effet, Weber, l'un des penseurs de plus grande influence sur la théorie des organisations a mis l'étude du pouvoir et du contrôle au centre de sa théorie et en a détaché trois formes de domination. Dans la domination charismatique le leader a un contrôle direct et personnel sur les subordonnés, alors que dans la domination traditionnelle sont les habitudes et les coutumes qui confèrent le pouvoir. Dans la domination rationnelle-légal, celle prédominante dans les organisations bureaucratiques, sont les règles et les lois qui donnent légitimité au pouvoir. Quelques auteurs (ETZIONI, 1965) utilisent le contrôle comme un équivalent du pouvoir, ce n'est pas le cas de tous les auteurs, mais aucune définition de contrôle laisse, d'une certaine manière, de faire référence au pouvoir, même si cela se fait implicitement.

Ainsi, Chiapello (1994) et Dermer (1988) définissent le contrôle par rapport à l'ordre. Chiapello (1994 : 157) défini le contrôle « comme une influence créatrice d'ordre ». Elle s'appuie sur Lebas (1980) pour dire que le contrôle a pour résultat la réduction des degrés de liberté des personnes. Si nous suivons les réflexions de Solè (2000) losqu'il pose la question : «chercher à réduire l'incertitude des actions humaines (à fermer le passé, le présent, le futur), n'est-ce pas s'éfforcer de réduire la liberté des humains ? », nous devrions parler d'essaie de réduction de la liberté.

Nous allons aussi nous appuyer sur Lebas et son affirmative pour définir le contrôle tel que nous le comprenons, c'est-à-dire comme un processus de réduction d'incertitude. Notre vision du contrôle est dirigé vers une perspective plus ample que celle du contrôle de gestion, nous prenons le contrôle organisationnel comme l'ensemble de dispositifs qui visent à réduire l'incertitude perçue par les individus dans une organisation, soient-ils des dispositifs concrets, comme la planification, ou ce que Bouchin (1988) appelle de contrôles invisibles, comme la culture. 
Nous faisons une liaison entre les degrés de liberté desquels parle Lebas et la «marge de liberté » présente dans la théorie de Crozier et Friedberg (1977). Ces auteurs ont construit une théorie ${ }^{2}$ selon laquelle, l'organisation est « un construit humain » ou « un ensemble humain structuré » (BERNOUX, 1985, p. 138). Cet ensemble sera structuré par l'interaction des acteurs qui jouissent d'une marge de liberté, qui est la ressource du pouvoir de laquelle disposent les acteurs, crée des zones d'incertitude dans l'organisation. Ces zones sont en rapport direct avec le pouvoir :

«... l'incertitude en général ou des incertitudes spécifiques... constituent la ressource fondamentale dans toute négociation. S'il y a incertitude, les acteurs capables de la contrôler l'utiliseront dans leurs tractations avec ceux qui en dépendent. Car ce qui est incertitude du point de vue des problèmes est pouvoir du point de vue des acteurs... » (CROZIER ET FRIEDBERG, 1977, p. 24)

Avec cette conception de marge d'autonomie des acteurs et de l'existence de zones d'incertitude dans l'organisation, Crozier et Friedberg contrarient la rationalité du système et donc l'existence d'une solution unique pour un problème, d'accord avec la théorie de Simon $(1945,1972)$. Nous partageons avec les auteurs (comme PAGES ET AL., 1987) l'existence de zones d'incertitude et de marge de liberté, c'est-à-dire d'autonomie des acteurs. Nous pensons aussi que cette autonomie peut être utilisée dans des stratégies de pouvoir. Mais nous sommes partiellement d'accord avec Pagès et al. (1987, p. 52) quand ils disent :

«nous réfutons l'analyse que fait Crozier de la manifestation par excellence des relations de pouvoir parce qu'elle occulte le fait que ces relations se situent dans un cadre prédéterminé. Cette analyse reproduit seulement la conception que l'organisation fait d'elle-même et qu'elle essaie d'imposer à ses employés ; les règles peuvent être contestées en visant la meilleur efficacité mais non comme un système de domination $»^{3}$

Nous sommes partiellement d'accord avec cette affirmative de Pagès et al. à cause de la rationalité qu'ils attribuent au système. Il nous semble que la perspective de Pagès et ses collaborateurs implique en la compréhension de qu'aucune liberté, à part celle déjà prévue par le système est laissée aux individus et cela suppose un système absolument rationnel. Cela est montré dans le passage où les auteurs contestent la vision de Crozier et Friedberg sur l'expression de la subjectivité des individus :

«... il ne veut pas voir que cette prétendue subjectivité locale des individus et des groupes dans l'organisation est destinée à se perpétuer. Elle est déjà programmée, dirigée, encadrée, assimilée par le système rationnel de règles. Qu'est-ce que c'est la subjectivité pour un responsable financier dont la fonction et toutes les règles de son exercice sont déterminées en dehors de lui ? »(PAGES ET AL., 1987, p. 53).

Nous pensons que l'expression «d'une irrésistible subjectivité» telle qu'elle est envisagé par Crozier et Friedberg doit être nuancée par la compréhension des prédéterminations de l'organisation, néanmoins nous ne pensons pas que l'organisation est porteuse d'une rationalité qui lui permet tout programmer, encadrer et assimiler. D'où notre conception de que le contrôle est la recherche de la réduction de l'incertitude, incertitude toujours existante dans l'organisation, justement parce que celle-ci ne peut pas tout prévoir, tout réglementer. Cette impossibilité n'exclut pas, cependant, la recherche inépuisable de la «maitrise du monde » (SOLE, 1996) et l'avancement de cette maîtrise.

Solé (1996, p.625) indique comme caractéristique du décideur moderne la volonté de maitriser le monde et que «vouloir maitriser le monde, c'est être convaincu que l'on peut (capacité), et que l'on doit (impératif), le contrôler ». Ce désir cherche à :

2 Nous n'allons pas explorer ici toute la richesse de la théorie de Crozier et Friedberg, mais utiliser quelques notions développées par les auteurs que nous semblent importante pour notre définition de contrôle.

3 Nous consultons l'ouvrage en portugais. 
«- maîtriser le Temps (on cherche à prévoir, à planifier, à anticiper, à se projeter dans la situation visée)

- maîtriser l'Autre (par exemple, afin d'obtenir des employés et des ouvriers les comportements et l'attitude désirés, les directions d'entreprise mettent en œuvre des démarches de plus en plus sophistiquées de motivation et communication)

- maitriser la Nature (en réponse à la montée des préoccupations écologiques dans la société, le 'management vert' suppose la possibilité et la nécessité d'intégrer les risques concernant l'environnement dans les décisions de l'entreprise)

- maitriser l'Espace (par exemple, afin d' 'optimiser' le prix du $\mathrm{m}^{2}$ de bureau, on conçoit une architecture en fonction des déplacements et des relations des personnes, supposés et prévus par les spécialistes)

- maîtriser la Technique (multiplication des paramètres pris en compte dans la conception des systèmes informatiques par exemple)

- se maîtriser Soi-même (afin de mettre en parenthèses ses émotions et son affectivité, le décideur sollicite une étude et des informations, tenues pour objectives). »

L'auteur souligne que ce désir de maîtrise du monde n'est pas une caractéristique exclusive des dirigeants d'entreprise, mais qu'il caractérise l'«être au monde » moderne. Appliquant cette notion aux experts qui aident la décision, Solé (1996, p. 626) pose la question sur l'idée que ceux-ci font de leur rôle qui procède de la croyance suivante: "plus de connaissance, plus de savoir, plus d'information = moindre incertitude = réduction des risques $=$ meilleure décision = plus grande maitrise (de la situation, du projet, de la stratégie) » (c'est nous qui soulignons).

C'est dans ce sens que nous faisons l'hypothèse des changements du contrôle organisationnel lors de transformations par lesquelles la plupart des organisations ont dû passé les dernières décennies. Nous pensons que certaines de ces transformations répondent à la perception des zones d'incertitude par les managers et qu'elles sont vues comme une réponse possible à la maitrise de ces zones. Néanmoins, nous n'attribuons pas aux managers une rationalité telle que les permettrait de : $1^{\circ}$ percevoir les zones d'incertitude, $2^{\circ}$ les problematiser, $3^{\circ}$ percevoir la réponse adéquate, $4^{\circ} 1^{\prime}$ implémenter comme la bonne solution. Nous pensons plutôt à l'incapacité de identifier clairement les zones d'incertitude (dans son ensemble) et à une recherche plutôt tattonante, où les problèmes et les réponses se construisent parallèlement. D'où notre vision de l'impossibilité d'une rationalité totale de la part de l'organisation que permettrait tout prevoir, mais d'une recherche constante dans cette direction.

\section{L'évolution du contrôle}

Le contrôle est au centre des réflexions sur les organisations. Encore que quelques auteurs comme Blau et Scott (1962) expliquent les organisations par la coopération des individus vers un objectif commun, d'autres, comme Simon (1945) opposent l'idée que les individus dans les organisations rarement ont des objectifs communs. Quoique soit la définition qu'on donne aux organisations le problème du contrôle s'impose. D'un côté on doit s'assurer que les actions individuelles mènent effectivement à l'objectif commun, de l'autre, que la diversité des objectifs n'empêche pas la réussite des objectifs organisationnels (ou que les obstacles posés par telle existence soient minimisés).

En ce que l'idée de contrôle est liée à celle de pouvoir et de domination, les études de Weber (1991) sur les types de domination, et notamment sur la domination rationnelle-légale assurée par la bureaucratie, sont fondamentales pour toute l'analyse organisationnelle que s'est développée après. 
D'après Carvalho (1998), le courant marxiste met aussi l'accent sur l'exercice de la domination et comprend le contrôle comme une nécessité créée par la contradiction conséquente à la séparation entre le travail et la propriété des moyens de production et «par la forme concrète de réalisation du processus de travail, laquelle exige une combinaison entre des matériaux, des moyens et des forces de travail ${ }^{4}$

L'auteur met en évidence que jusqu'à l'émergence du système de manufacture, la structure de contrôle était formée par un ensemble complexe de coutumes et traditions. Le système de manufacture révolutionne ce système en séparant le travailleur des moyens de production et en concentrant la main-d'œuvre dans les manufactures urbaines où le contrôle simple était employé.

La croissance de telles entreprises donne lieu à une nouvelle forme d'organiser le travail, appelée organisation scientifique du travail et développée par Taylor (1971). Pour résumer l'ouvre assez connue de Taylor nous nous limiterons à évoquer les trois principes de l’OST selon Braverman.

Le premier principe est celui de la «dissociation du processus de travail et de l'art de l'ouvrier». A travers celui-ci l'entreprise devait s'approprier du savoir ouvrier à fin d'imposer de méthodes plus rapides, mises à jour à travers des études systématiques. Le deuxième principe est celui de la séparation entre la conception et l'exécution du travail. Le troisième est la planification du travail. Braverman (1983, p. 386) synthétise :

«... si le premier principe est le rassemblement et le développement de connaissances sur les processus de travail, et si le second est la concentration de cette connaissance, qui devient le secteur réservé de la direction des entreprises - allié à son contraire essentiel, l'absence d'une telle connaissance parmi les ouvriers -, le troisième principe est l'utilisation de ce monopole du savoir pour contrôler chaque pas du processus de travail et son mode d'exécution» (souligné par l'auteur).

Le contrôle exercé jusqu'à cette période peut être compris dans la classification d'Edwards (1981) comme le contrôle simple qui s'exerçait de façon interpersonnelle et directe. La suite du développement du taylorisme par le fordisme introduit ce que l'auteur appelle contrôle technique, qui est celui imbriqué dans la technologie utilisée par la firme. Le troisième type c'est le contrôle bureaucratique, que selon Carvalho (1998) «utilise des mécanismes indirects et moins visibles du contrôle lorsqu'il inscrit la réglementation des activités, la spécialisation, la hiérarchie et la division du travail en un ensemble de mécanismes structuraux objectifs et impersonnels ». Plusieurs ont été les études réalisés sur la bureaucracie, ceux de Weber, bien évidemment, ont été la base pour la constructions des autres, comme Blau e Scott (1962), Merton ainsi que les études du Groupe d'Aston, en Anglaterre. Nous verrons les caractéristiques du contrôle bureaucratique dans la prochaine séction.

On peut identifier aussi un autre type de contrôle qui qui est construit avec le développement des organisations modernes, le contrôle professionnel, exercé par les normes des professions auxquelles les individus sont formés à travers un long processus d'éducation formelle. Ces professionnels partagent des connaissances et des valeurs, intériorisés au long de leur processus de formation, qui dépassent la frontière des organisations. Ce mode de contrôle s'approche de celui que nous prétendons étudier ici, le contrôle à travers la culture, en ce que les valeurs sont intériorisées par les individus. Néanmoins, le contrôle professionnel est restreint à certaines catégories professionnelles qui subissent un long processus de formation et n'est pas formé directement en rapport avec une organisation, comme c'est le cas du contrôle à travers la culture. Il faut préciser, encore que le contròle professionnel soit construit et interiorisé au long des processus de formation des professionnels, c'et bien dans une organisation plus ou moins bureaucratique qu'il va être mis en place.

L'évolution du contrôle ne fait pas disparaître les modes utilisés antérieurement, ainsi on peut jusqu' aujourd'hui identifier le contrôle direct dans plusieurs organisations, à travers la supervision. Les diverses façons d'exercer le contrôle peuvent êtres toutes trouvées dans une même organisation, la variation lors de leur utilisation se doit aux caractéristiques de l'entreprise et du travail y réalisé, ainsi qu'à l'environnement. Dans ce sens, lorsqu'on parle du contrôle organisationnel, il nous semble plus adéquat de parler d'un mix du contrôle,

\footnotetext{
${ }^{4}$ En Espagnol dans l'originel.
} 
puisqu'on ne trouvera pas un mode de contrôle en action, mais un ensemble de modes qui varient à l'intérieur de l'organisation.

Plus récemment la littérature met en évidence le développement d'une nouvelle forme de contrôle que, dans la classification de Mintzberg (1982), serait l'organisation missionnaire, dont le mécanisme de coordination est la socialisation. Cela correspondrait à ceux que d'autres auteurs appellent le contrôle par la culture, par les valeurs, ou contrôle social (O'REILLY ET CHATMAN, 1996). Un contrôle plus flou et moins perceptible. Cette forme de contrôle a tendance à éliminer les coûts du contrôle hiérarchique et bureaucratique, mais peut, d'après quelques auteurs (OUCHI, 1978), mener l'organisation à une rigidité en ce qui concerne l'innovation car l'homogénéité de la vision du monde clôture les façons de penser. Si d'une part l'exposition que fait Mintzberg sur ce mode de controle peut être interessante puisqu'il éclairci certainnes discussions de l'epoque de son travial, d'un autre on ne peut pas faire hypothèse de que seulement dans l'organisation dite missionaire une l'ideologie jouerai un rôle important. L'organisation capitaliste moderne est elle même une ideologie et n'importe à quelle époque a essayé par differents moyens de convaincre les hommes et les femmes des valeurs qu'elle répresente.

On peut faire une synthèse de cette évolution à travers un passage de Aubert et Gaulejac (1989) :

«Si nous reprenons les enjeux du management tels qu'ils se présentaient au début du XXème siècle, notamment à travers tout le travail accompli par Taylor pour rationaliser la production en instaurant l'Organisation Scientifique du Travail, nous pouvons dire brièvement que l'enjeu majeur, sur le plan humain, c'est alors le contrôle et la rationalisation de l'énergie physique des individus. On peut résumer cette idée d'une façon un peu abrupte en disant qu'il s'agit d'un management des corps, c'està-dire que l'enjeu du contrôle est le corps de l'homme qu'il s'agit de porter à son potentiel maximum d'utilité, de rentabilité et de performance.

Si nous prenons ensuite les préoccupations du management, telles qu'elles apparaissent après les célèbres expériences de Hawthorne (quelle que soit d'ailleurs la validité scientifique de ces expériences) et telles qu'elles vont se manifester à travers tout le mouvement des Relations Humaines, nous pouvons dire que l'enjeu du contrôle se déplace ici du registre du corps à celui de l'affectif et du cœur : on essaie de comprendre de quelle façon la dimension affective opère dans l'entreprise, on essaie de percer les secrets de la motivation et de promouvoir un mode de leadership adéquat qui tienne compte précisément de cette dimension humaine et affective (travaux de Maslow, Herzberg, Mac Gregor, likert, Blake et Mouton, ...). Là encore, pour résumer brièvement, nous pouvons dire que l'on assiste à la mise en place d'un management des coeurs dont l'enjeu semble être la compréhension et la maîtrise de la dimension affective de l'individu.

Enfin, si nous prenons à présent les préoccupations du management, telles quelles apparaissent depuis la fin des années 60 (à travers entre autres l'extraordinaire essor du management par la culture), on peut les résumer - là aussi schématiquement - en disant que l'enjeu du contrôle s'est déplacé sur le registre psychique et qu'il s'agit en quelque sorte de contrôler et d'utiliser au mieux l'énergie psychique des individus en s'efforçant d'abord de capter leur imaginaire puis, ensuite, de le canaliser sur des objectifs bien précis de production de performance. »

\section{Les modes de contrôle}

D'après Clegg (1987 : 404) le contrôle comporte trois objectifs dans la perspective d'Edwards : «(1) diriger les tâches ; (2) évaluer le travail réalisé ; et (3) récompenser et punir les travailleurs ».

Hatch (1997) prend la définition de Tannenbaum (cité ci-dessus) comme la synthèse de la vision moderniste du contrôle organisationnel, pour laquelle le contrôle doit être exercé afin de minimiser l'impact des intérêts divergents des individus qui font partie de l'organisation sur leurs actions. L'auteur présente trois théories 
modernistes : le modèle cybernétique, la théorie de l'agence et la théorie des formes organisationnelles d'Ouchi.

Dans le modèle cybernétique on compare deux états de l'organisation, le courant et le souhaité, les différences entre les deux donnent lieu à des ajustements. Ces théories font appel à l'exemple du thermostat qui identifie la température ambiante et la compare avec la température désirée effectuant les actions nécessaires à l'ajustement. Dans les organisations il revient au management d'établir les façons d'identifier l'état courant, de mesurer les résultats des actions menées afin de pouvoir le comparer à l'état souhaité. D'après Chiapello (1994) cela présuppose que le processus de contrôle est maîtrisable.

La théorie de l'agence se soucie du mode d'assurer aux actionnaires (principals) que les actions entreprises par les managers (agents) sont d'accord avec leurs intérêts, donc de contrôler ces actions. Le problème étant que les managers peuvent poursuivre leurs propres intérêts. Comme le souligne l'auteur, cette théorie porte plutôt sur les relations extérieures à l'organisation, si on considère les actionnaires comme ne faisant pas partie de celleci, mais elle peut être appliquée aussi au fonctionnement intérieur de l'organisation. Le contrat est la façon par laquelle les actionnaires peuvent résoudre la question de l'accord entre actions menées par le management et leurs intérêts. Le contrat écrit a pour but d'aligner les intérêts des agents avec les intérêts des actionnaires à travers les spécifications des mesures et des récompenses. Ainsi, l'agent sert ses propres intérêts au fur et a mesure qu'il sert les intérêts des actionnaires puisqu'il est récompensé par les performances des activités qui servent leurs intérêts. L'auteur souligne qu'une partie du risque d'entreprendre devient, dans ce cadre, à l'agent, puisqu'il sera récompensé ou puni par les performances des activités pour lesquelles il y a des variables qu'il ne contrôle pas.

L'auteur indique la variété des modes de contrôle présentés par Eisenhardt :

«The first is to design a simple, routine job so that behaviors can be easily observed, and to reward based upon behaviors. The second control strategy is to design a more complex, interesting job and invest in informations systems(e.g., budgeting systems, audits, or additional layers of management) in order to gain knowledge about behaviors, and to reward based on these behaviors. The third alternative is to design more complex, interesting jobs, but use a much simpler evaluation scheme (e.g., profitability, revenues), and reward based upon the results of the evaluation. In this strategy, higher, but riskier rewards are subtituted for measures, and precise job design. Finally, Eisenhardt describes a fouth option that moves away from the emphasis on performance evaluation and focuses instead on eliminating the divergent interests that give rise to the need for performance evaluation in the first place. This is the idea of using selection, training, and socialization as alternatives to cybernetic control systems... » (HATCH, 1997, p.337).

La dernière alternative amène à la théorie d'Ouchi sur les marchés, bureaucraties et clans. Ouchi $(1979$, p. 845) défini le contrôle comme le problème de «achievieng cooperation among individuals who hold partially divergent objectives ». La façon de résoudre ce problème dans les organisations prend trois formes différentes: le marché, la bureaucratie et le clan.

Le contrôle par le marché peut être utilisé dans un environnement compétitif où les prix et le profits assurent les mesures de performance. A l'intérieur de l'organisation ce type de contrôle peut être utilisé en créant de centres de profit qui seront en compétition avec d'autres fournisseurs extérieurs, par exemple. Si la compétition n'est pas présente, ou ne peut pas être simulée, l'organisation fera appel au mode de contrôle bureaucratique.

Le contrôle bureaucratique cherche à normaliser les comportements à travers une combinaison de règles, procédures, documentation et surveillance. Les règles bureaucratiques établissent les façon de conduire un processus, la surveillance assure le respect de ces règles. Ouchi (1980) voit dans l'organisation bureaucratique deux avantages par rapport au marché :

« first, it uses the employment relation, which is an incomplete contract. In accepting an employment relation, a worker agrees to receive wages in exchange for submitting to the legitimate right of the or- 
ganization to appoint superior officers who can (1) direct the work activities of the employees form day to day (within some domain or zone of indifference), thus overcoming the problem of dealing with the future all at once and (2) closely monitor the employee's performance, thus minimizing the problem of opportunism... Second, the bureaucratic organization can creates an atmosphere of trust between employees much more readily than a market can between the parties to an exchange. »

Ce type de contrôle donne lieu à une échelle hiérarchique relativement longue, puisqu'il faut surveiller les surveillants et ainsi de suite. En plus le contrôle bureaucratique ralenti les processus organisationnelles, tels que la prise de décision. Il est donc inadéquat à un environnement changeant et incertain où la réaction de l'organisation doit être rapide. Ouchi (1980, p. 135) signale que pour servir efficacement de médiateur des transactions une organisation doit «reduce either the ambiguity of performance evaluation or the goal incongruence between parties ».

Pour un environnement changeant, incertain et ambigu, Ouchi (1979) attribue le contrôle par le clan comme le plus adéquat. Ce système est basé sur les valeurs culturelles, les normes et les expectatives comme mécanismes primaires de contrôle. Il agit à travers l'internalisation des normes par les individus pendant leur processus de socialisation. Cette forme de contrôle montre un degré élevé de discipline que, d'après Kanter (cité par OUCHI, 1980), n'est pas atteint à travers les contrats ou la surveillance mais à travers une forme extrême de croyance que les intérêts individuels sont mieux réussis par une immersion complète de l'individu dans les intérêts du groupe. Pour Ouchi (1980) cette organisation est typique dans les industries fortement intégrées ou technologiquement avancées, où le travail en groupe est commun et les technologies changent rapidement faisant la performance individuelle ambiguë.

Le contrôle par le clan, ainsi que le contrôle bureaucratique, crée un système de légitimation de l'autorité, mais dans le clan il est plutôt traditionnel alors qu'il est rationnel-legal dans la bureaucratie. Ce système, d'après Ouchi (1980) se différentie de la bureaucratie fondamentalement parce qu'il ne demande pas d'évaluation et des audits explicites. L'évaluation de la performance est faite par les pairs à travers un système qui ne peut pas être traduit en des mesures vérifiables. Les trois modes de contrôle décrits par Ouchi sont présentés selon leurs exigences normatives et d'information dans le tableau ci-dessous. Les exigences normatives font référence aux accords que les membres doivent partager pour que le système fonctionne de manière efficiente.

Une des façons de garantir le contrôle par le clan c'est le développement d'une stratégie de sélection et de promotion d'après les valeurs établies par le top management. Dans ce cas la surveillance n'est pas nécessaire puisque les valeurs des individus sélectionnés les amènent à adopter un comportement conforme aux expectatives de l'organisation . Ouchi $(1980: 139)$ dit des valeurs et croyances :

«Common values and beliefs provide the harmony of interest that erase the possibility of opportunistic behavior. If all members of the organization have been exposed to an apprenticeship or other socialization period, then they will share personal goals that are compatible with goals of the organization. In this condition auditing of performance is unnecessary except for educational purposes, since no member will attempt to depart from organizational goals ».

L'utilisation d'un tel type de contrôle est vue par l'auteur comme une façon de dépasser à la fois l'ambiguïté des informations lors des échanges contrôlés par le marché, et le coût de la surveillance dans la bureaucratie.

En suivant la typologie de Ouchi, en ce qui concerne notre problématique, c'est-à-dire les changements du type de contrôle effectués après l'implémentation nouvelles téchniques d'organisation du travail, dans le mix du contrôle organisationnel, le mode de contrôle par le clan prendrait davantage d'importance. Cela comme nous l'avons déjà souligné ne présuppose pas la disparition des autres types de contrôle. Ainsi, les contrôles bureaucratiques et les contrôles par le marché seront toujours présents. Il se peut aussi que le contrôle par le clan prenne de l'importance ainsi que d'autres, comme les contrôles bureaucratiques. C'est-à-dire que la prise d'importance du contrôle par le clan ne signifie forcement la diminution de l'importance de tous les autres types de contrôles. On peut, par exemple, voir que quelques aspects du contrôle par le marché prendront de l'importance lors de l'implémentation de certainnes des nouvelles téchniques, telles que le management de la 
Qualité Totale ou la Assurance Qualité effectuée par les normes ISO. Ainsi les auteurs du MQT mettent l'accent sur la place du client et sur la préoccupation que doivent avoir les membres organisationnels dans son ensemble avec les attentes des clients. De la même façon, le processus de certification (série ISO 9000), mise en place par un grand nombre d'organisations, peut mettre en relief quelques aspect du contrôle bureaucratique, à travers les documents de suivi des processus, exigés pour les organismes de certification.

Hatch (1997) développe la question posé par la culture à travers le clan, sur la possibilité qu'auraient les managers de contrôler la culture. Nous avons déjà eu l'opportunite de de discuter cette question dans d'autres travaux. Par l'instant il nous soufi de clarifier que le courant de l'interpretativism symbolique s'oppose à cette possibilité en concluant que c'est la culture que contrôle les managers et non le contraire.

En suivant la distinction de Hatch, nous allons aborder deux autres courants d'études du contrôle que acceptent la thèse du contrôle par le clan, le courant marxiste et les théories postmodernes. Ils s'attaquent à l'aspect moral d'un tel contrôle sur la base de la similarité entre les mécanismes du contrôle par le clan et l'idée de «fausse conscience » développée par Marx. Selon Hatch (1997, p. 343) «false consciousness occurs when one group within a social structure, such as workers, participates in their own exploitation by recognizing the legitimacy of their oppressors' right to dominate them ».

La fausse conscience est en relation avec deux autres idées centrales pour la théorie neo-marxiste des organisations. L'hégémonie qui concerne le pouvoir qu'un groupe social exerce sur un autre, et l'idéologie, définie comme un système d'idées qui légitime la domination d'un groupe sur un autre (HATCH, 1997). La domination culturelle est vue donc comme un processus de construction de consensus à travers un système symbolique crée pour soutenir et communiquer l'idéologie. D'après Hatch (1997, p. 343) :

« it is this engineered consensus that gives rise to false consciousness and forms the focus of vigorous critiques of culture change programs, total quality management, business process re-engineering, and other popular managerial initiatives that use the rhetoric of participation to enlist the support of workers ».

Dans ce sens Van Maanen et Kunda (1989) disent que la culture implique un contrôle subtil des émotions des employés et le discours de la culture organisationnelle masque la tentative des managers de contrôler, non seulement ce que les employés disent et font, mais aussi ce qu'ils sentent. L'argument des auteurs est que les managers essayent de construire une culture dans l'organisation comme un moyen subtil et puissant de contrôle. Ils expliquent :

«It is subtle because culture is typically regarded as something people can do little about, something that flows from the ordinary problems people face and the characteristic ways they solve them... It is powerful because it seemingly aims at a deeper level of employee compliance (i.e., emotional) than other forms of control (Van Maanen et Kunda, 1989, p. 88). »

Les auteurs, d'après Hatch (1997), ne supposent pas la possibilité d'éviter des processus de pouvoir et domination dans les interactions sociales mais trouvent utile de prendre conscience des effets de ces processus. Dans ce sens l'auteur cite un passage de Czarniawska-Joerges :

« [Autonomy] offers organizations flexibility and creativity, which are essential for adaptation to changing environments... Without autonomy, organizations become rigid and obsolete. [On the other hand,] Control of others offers organizations predictability, which is necessary to produce standardized outputs and to coordinate actions... Without control, organizations is invaded by chaos and deadly entropy. »

Les auteurs post-modernistes, de leur côté vont soutenir une autre thèse. Pour le contrôle est une ideologie, comme l'affirme Hatch (2000, p. 362) :

« La croyance dans le caractère essentiel du contrôle pour le succès des organisations, comme y invite la vue moderniste de Tannembaum..., légitimise, dès lors, le droit de puissance à dominer. Cette 
croyance peut être caractérisée d'idéologique, et plus précisément d'ideologie du contrôle. Réinterpréter toutes les théories des organisations sous l'angle de l'idéologie s'inscrit dans l'un des projets des théoriciens post-modernistes des organisations ».

Une autre typologie du contrôle organisationnel déjà classique dans les études sur les organisations est celle de Mintzberg. L'auteur avait dans une première œuvre (MINTZBERG, 1982) identifié cinq configurations organisationnelles, auxquelles correspondaient des systèmes de coordination. C'est-à-dire que les organisations utiliseraient plusieurs stratégies de coordination d'entre lesquelles une prédominerait en fonction de leur configuration. Plus tard (MINTZBERG, 1989), l'auteur ajoute deux autres configurations.

Dans cette typologie « chaque configuration possède son propre équilibre autour d'une force dominante qui structure le champ des relations » (AMBLARD ET AL., 1996, p. 15). Il en a six points d'appui possibles : le sommet stratégique, le centre opérationnel, la ligne hiérarchique, la technostructure, le support logistique, l'idéologie. Nous allons la commenter surtout par rapport à notre centre d'intérêt, le contrôle.

La première configuration celle de l'organisation entrepreneuriale s'appuie sur le sommet stratégique, le contrôle est caractérisé par la supervision directe. «La structure est donc centralisée, simple, informelle, flexible, avec peu de place pour la ligne hiérarchique et les supports logistiques » (AMBLARD ET AL., 1996, p. 16).

L'organisation mécaniste s'appuie sur la technostructure, c'est une structure de type bureaucratique où «la rationalisation favorise le contrôle » (AMBLARD ET AL., 1996, p. 16). Ce contrôle est réalisé à travers la standardisation des procédés. Mintzberg (1982) suggère que cette configuration a une obsession : le contrôle. Dans ce type d'organisation le contrôle déborde le centre opérationnel et s'étend à toute l'entreprise, à travers les règles, les procédures, la communication formelle et les lignes formelles de la hiérarchie.

L'organisation divisionnalisée s'appuie sur la ligne hiérarchique. Le système de contrôle est fondé sur la standardisation des résultats, agissant donc sur les performances. Néanmoins, la standardisation des qualifications et la supervision directe peuvent aussi jouer un rôle limité.

La quatrième configuration, l'organisation professionnelle a comme force dominante le centre opérationnel. «Marquée par une forte problématique de l'autonomie et de l'expertise, cette forme d'organisation réalise sa coordination à travers la standardisation du savoir et des qualifications » (AMBLARD ET AL., 1996, p. 17). La formation et la socialisation sont des paramètres de conception importants pour cette configuration puisqu'elle « recrute des spécialistes dûment formés et socialisés - des professionnels - pour son centre opérationnel, et leur laisse une latitude considérable dans le contrôle de leur propre travail » (Mintzberg, 1982, p. 310). Mintzberg marque sa différence par rapport aux organisations mécanistes :

«Alors que dans la Bureaucratie Mécaniste, les standards sont une création interne de la technostructure dont les cadres opérationnels imposent le respect aux opérateurs, les standards de la Bureaucratie Professionnelle sont élaborés pour une large part en dehors de la structure, dans des associations professionnelles autogérées auxquelles les opérateurs de l'organisation adhèrent tout comme leurs collègues des autres Bureaucraties Professionnelles. Ainsi, alors que la Bureaucratie Mécaniste est fondée sur l'autorité de la position (qui est de nature hiérarchique), la Bureaucratie Professionnelle met l'accent sur le pouvoir de la compétence (qui est de nature professionnelle) ».

Les organisations innovatrices ont comme force dominante les fonctions de support logistique. Comme son nom indique, cette organisation est centrée sur l'innovation et la solution des problèmes «ad hoc » (Mintzberg l'appelle aussi adhocratie). Cette organisation, comme la professionnelle, recrute des professionnels, néanmoins elle ne peut pas compter sur la standardisation du savoir, puisqu'elle a besoin de connaissances nouvelles et différentes mises en relation pour des projets innovants. Le mécanisme de coordination est l'ajustement mutuel. Mintzberg (1982, p. 378), cite Khandwalla (1976) :

« le travail de coordination n'est pas laissé à un petit groupe de responsables, mais assumé par la plupart des membres de l'organisation, de façon assez semblable à ce qui se passe dans une équipe de 
hockey ou de cricket bien intégrée où les membres associent spontanément leurs efforts de façon à garder les activités de l'équipe centrées sur leur objectif qui est la victoire».

Dans son ouvrage de 1982, Mintzberg annonçait la possibilité d'une sixième configuration qui serait une structure hybride, possédant des caractéristiques des organisations mécanistes, professionnelles, divisionnalisées et de l'adhocratie. Son mécanisme de coordination serait la socialisation, ou la standardisation des normes et le paramètre de conception principal, l'endoctrinement. Cette organisation aurait une sixième partie qui serait l'idéologie. Dans son ouvrage de 1989, Mintzberg inclut cette sixième configuration, que, d'après lui, est apportée par les japonais. Il utilise le terme idéologie, dans le sens d' « un système riche développé et profondément enraciné de valeurs et de croyances qui distingue une organisation particulière de toutes des autres » (MINTZBERG, 1989 : 320) . Il envisage l'identification comme un remplaçant possible des mécanismes plus traditionnels de la supervision directe ou de la standardisation des procédés de travail, des résultats et des qualifications pour la coordination. Puisque cette configuration est la plus proche du contrôle à travers la culture, nous allons la développer davantage dans la section sur ce type de contrôle.

La dernière configuration, l'organisation politique est caractérisée par «un manque de toute forme d'ordre que l'on trouve habituellement dans les organisations conventionnelles » (MINTZBERG, 1989 : 348). L'auteur dit, que cette configuration doit être décrite en termes de pouvoir et non de structure, un pouvoir qui, pour lui, est exercé d'une façon illégitime dans les organisations conventionnelles. Donc, cette configuration n'a pas de méthode de coordination préférée, ni de partie dominante, ni, non plus de type clair de décentralisation. D'après lui, «tout dépend de la fluidité du pouvoir informel, canalisé pour gagner sur des sujets individuels » (MINTZBERG, 1989 : 348).

En suivant la typologie de Mintzberg, d'après notre hypothèse centrale, les organisations qu'ont implanté le MQT auraient tendance à donner plus de place dans son mix de contrôle au système de coordination de la configuration missionnaire.

Une autre typologie du contrôle est celle de Child (1984) qui fait référence directe, au contraire des autres, au contrôle culturel. Il identifie quatre stratégies de contrôle :

- Contrôle personnalisé centralisé - regroupe la supervision hiérarchique directe, la centralisation des décisions et l'autorité personnelle fondée sur l'expertise ou le charisme ;

- Contrôle bureaucratique (impersonnel) - fondé sur la spécialisation des tâches, l'utilisation de règlements, de procédures, de contrôles comptables et budgétaires et l'automatisation du travail.

- Contrôle des outputs - fondé sur des centres de responsabilité découpés de façon à les responsabiliser sur un output, la fixation d'objectifs, l'utilisation d'une comptabilité par responsables et la délégation des décisions ;

- Contrôle culturel - fondé sur le développement d'une forte identification aux buts des dirigeants, une certaine autonomie, peu de contrôles formels, et qui met un fort accent sur le recrutement, la formation et le développement du personnel.

Czarniawska-Joerges propose une théorie du contrôle où l'évolution est comprise comme allant naturellement du contrôle coercitif, vers le calculatif et, ensuite vers l'idéologique. Sa typologie est fondé sur celle d'Etzioni assez connueNous présentons ci-dessous un tableau avec sa typologie construite sur la base des études de Etzioni.

Les prescriptions de Taylor pour le Management Scientifique du Travail sont l'exemple le plus connu de ce qu'on appelle le contrôle direct. Dans ce mode de contrôle un ébauche de planification des activités est rendu au responsable de l'équipe. L'autorité de ce responsable vient du rôle qu'il représente dans l'organisation, mais elle peut aussi être fondée sur son habilité personnelle à entretenir les relations avec les membres de l'équipe, en complément de son rôle formel. Ce responsable veillera sur les membres de l'équipe afin de s'assurer que ce qu'ils font est d'accord avec les ordres, il veillera à la façon de faire, à la quantité, et à la discipline de ces 
ouvriers. Les membres de l'équipe sont formellement dépourvus de toute participation à d'autres activités que celles de l'exécution des tâches que leurs ont été ordonnés, leur attitude est donc l'aliénation, comme l'a expliqué Etzioni. Le contrôle est exercé pendant l'action, c'est-à-dire sur l'individu lui-même pendant qu'il réalise ses activités.

Tableau 2 - Typologie des organisations et mécanismes de contrôle

\begin{tabular}{|c|c|c|c|c|c|}
\hline $\begin{array}{l}\text { Type de } \\
\text { organisations }\end{array}$ & $\begin{array}{l}\text { Cible du } \\
\text { contrôle }\end{array}$ & $\begin{array}{l}\text { Base } \\
\text { d'engagement }\end{array}$ & $\begin{array}{l}\text { Prototype des } \\
\text { organisations }\end{array}$ & $\begin{array}{l}\text { Moyens de } \\
\text { contrôle }\end{array}$ & $\begin{array}{l}\text { Exemples } \\
\text { pratiques }\end{array}$ \\
\hline Total & Corps physique & coercitif & $\begin{array}{l}\text { prisons } \\
\text { Asiles }\end{array}$ & $\begin{array}{l}\text { Force } \\
\text { Menaces } \\
\text { Sanctions }\end{array}$ & Licenciements \\
\hline Economique & Comportement & Calcule & $\begin{array}{l}\text { Business } \\
\text { Bureaucraties }\end{array}$ & $\begin{array}{l}\text { Primes } \\
\text { Supervision } \\
\text { Règles } \\
\text { Technologie }\end{array}$ & $\begin{array}{l}\text { Payement par } \\
\text { pièce } \\
\text { Promotion } \\
\text { Commission }\end{array}$ \\
\hline Idéologique & Vision du monde & Identification & $\begin{array}{l}\text { Politique } \\
\text { Religieuse }\end{array}$ & $\begin{array}{l}\text { Buts attractifs } \\
\text { Persuasion } \\
\text { Sens } \\
\text { d'appartenance } \\
\text { Réduction de } \\
\text { l'incertitude }\end{array}$ & $\begin{array}{l}\text { Vision du } \\
\text { Management } \\
\text { Propagande }\end{array}$ \\
\hline
\end{tabular}

Source : Hatch (1997).

Les mécanismes du contrôle peuvent être envisagés à la fois comme le contrôle par l'expert, en considérant que le superviseur est celui qui possède la connaissance de ce que doit être réalisé, et routinier, puisque les tâches ont été parcellisées et elles sont répétitives. Néanmoins, les organisations qui utilisent ce mode de contrôle comptent souvent sur un bureau de temps et méthodes, où se trouvent les experts que, malgré leur pouvoir sur les activités, ne exerceront pas le contrôle directement sur les ouvriers, mais par l'intermédiaire des déterminations sur les méthodes. Nous allons donc considérer les mécanismes de ce contrôle comme ceux du contrôle routinier.

Le contrôle bureaucratique, largement exploré dans la littérature organisationnelle ${ }^{5}$, s'exerce surtout à travers l'organisation, par son arsenal administratif et mécanique. Ici on trouve les règlements, les procédures, la division formelle du travail, la hiérarchie, la structure formelle de l'organisation. Le contrôle se fait en trois moments : avant l'action, à travers la planification, l'établissement des règlements et des procédures, ainsi qu'à travers la sélection des personnes; pendant l'action à travers la hiérarchie et après l'action à travers le contrôle des résultats. La réaction des contrôlés, comme l'a décrit Etzioni est la relation instrumentale. Les procédés de travail, la qualification du personnel et les résultats sont les objets d'un contrôle routinier et par expert. Le contrôle bureaucratique peut être mesuré par les variables de la structure organisationnelle, puisque dans ce mode le sujet de contrôle est l'organisation. Kalika (1988) présente cinq variables de structure organisationnelle que nous avons résumé dans d'autres travaux (SILVA, 1999).

\subsection{Le contrôle à travers la culture}

Deleuze (1990) attire l'attention pour les changement du contrôle dans nos sociétés. D'après lui les sociétés disciplinaires analysées par Foucault sont en train de donner lieu à ce qu'il appelle les sociétés de contrôle. Les sociétés disciplinaires se caractérisaient par l'enfermement des gens dans l'école, les hôpitaux, les prisons et les usines dont le projet, particulièrement visible dans l'usine, était de «concentrer; répartir dans l'espace ; ordonner dans le temps ; composer dans l'espace-temps une force productive dont l'effet doit être supérieur à la somme des forces élémentaires » (DELEUZE, 1990 : 240). La crise de ces milieux d'enfermement nous amène

\footnotetext{
${ }^{5}$ Voir notamment les travaux du Groupe d'Aston : Hickson et al. (1969 et 1971), Hinnings et al. (1971), Pugh et al. (1968 et 1969) ainsi que Child (1972).
} 
à la société de contrôle qu'il décrit comme un « moulage auto-deformant qui changerait continûment » (242). Il exemplifie par l'usine :

«On le voit bien dans la question des salaires : l'usine était un corps qui portait ses forces intérieurs à un point d'équilibre, le plus haut possible pour la production, le plus bas possible pour les salaires ; mais, dans une société de contrôle, l'entreprise a remplacé l'usine, et l'entreprise est une âme, un gaz ».

Les changements vus dans les organisations aujourd'hui peuvent être en relation avec ce que Deleuze analyse dans son essai à travers un contrôle plus flou, plus subtil et mis en place dans les organisations qui cherchent à utiliser la culture comme un moyen de contrôle.

L'intérêt par le sujet a été déclenché par la publication de l'ouvrage de Peter et Waterman, Le Prix de l'Excellence. Dans cet ouvrage les auteurs décrivent le comportement des membres de plusieurs entreprises nord-américaines, considérées excellentes, et leurs démarches pour maintenir un comportement susceptible d'amener à ce degré d'excellence. Ce récit a donné lieu à un débat sur la possibilité de gérer la culture qui est au centre des discussions sur le contrôle à travers la culture.

On trouve d'un côté des théoriciens, comme Amado (1988) pour qui le management de la culture « est de l'ordre de l'impossible». Ces théoriciens, souligne Hatch (1997: 234 ), argumentent qu' une fois que « les normes et les valeurs sont basées sur des assomptions basiques et croyances qui ne sont pas mises en question profondément enracinées, les possibilités de manager la culture sont très fortement limitées ».

Ceux qui pensent que la culture peut être gérée, appuient leur argumentation sur le rôle du manager, son influence et sa place privilégiée par rapport à la structure de pouvoir. Les managers, étant le membres le plus influents de la culture organisationnelle, seraient en mesure d'établir des modèles de comportement. Cela dit, le résultat de cette influence n'est pas garanti.

Hatch (1997) dit que la perspective symbolico-interpretative offre un chemin qui est entre les deux antérieurs. Elle argumente que les managers ont le potentiel de devenir des symboles puissants dans les organisations, donc ils représentent le signifiant que les outres membres associeront à l'organisation. Dans ce cas le signifiant attribué dépendra des interprétations faites par les autres membres, d'où on peut dire que le succès du leadership dépend de son adéquation aux schémas interprétatifs qui constituent la culture organisationnelle. Hatch $(1997: 235)$ résume :

« this argument recognizes that managers are themselves part of the culture and are, therefore, likely to be managed by cultural influence even while they are trying to be managers of the culture. In other words, managers are artifacts who would like to be symbols ».

L'auteur remarque donc l'importance de penser au contexte culturel dans lequel on organise des changements, plus que de penser au management de la culture elle même, ce qui pourrait aboutir à des conséquences inattendues de la part des employés.

Nous sommes d'accord avec les auteurs symbolique-interpretatifs en ce qui concerne l'influence de la culture sur les managers et que cette influence limite leur capacité de gérer la culture. Néanmoins, nous pensons que cela n'est qu'une limitation qui n'empêche pas la tentative d'utiliser la culture comme un moyen de contrôle en essayant d'agir sur elle. Cette action ne pourrait pas être minutieusement planifiée par rapport à un but, puisqu'étant donné l'interaction des actions avec l'interprétation des individus on ne pourrait pas connaître d'avance les résultats. Cependant, la position de pouvoir des managers leur donne la possibilité d'agir sur des éléments et des processus organisationnels qui ont de l'influence sur la culture et peuvent apporter des changements.

Outre aspect à considérer, toujours dans la perspective de la position de pouvoir, c'est l'interprétation des événements faite par les managers. Ces interprétations seront transmises à travers le processus de communication organisationnelle, à travers la formation interne, le travail en groupes, les réunions formelles et informelles dans le but de les faire partager par la majorité des membres. Il y a une forte possibilité que les 
managers aboutissent à ce but à cause du manque d'informations nécessaires à la formation d'autres interprétations ressenti par les employés. Néanmoins, ils peuvent interpréter les interprétations des managers, ce qui nous empêche de penser le management de la culture d'une façon achevée.

La position que nous prenons dans cette étude partage donc deux des visions sur le thème. Nous pensons que les managers peuvent exercer une influence puissante sur la culture et essayer de la gérer en la transformant en un moyen de contrôle. Mais ils sont limités dans cette action par l'influence qu'elle exerce sur eux et par les interprétations des autres membres de l'organisation.

Cette position étant explicitée, nous aborderons ensuite des travaux réalisés sur le thème du contrôle à travers la culture en essayant de mettre en évidence les mécanismes à travers lesquels ce type de contrôle agit.

Comme nous avons déjà abordé, rapidement, dans la section antérieure, Mintzberg, dans son ouvrage de 1982, esquissait déjà une sixième configuration qui compléterait les cinq qu'il avait construit et que se montrait à peine à cette époque. Nous allons ici, à travers son ouvrage de 1989, discuter plus profondément les mécanismes de cette configuration.

Mintzberg préfère le terme d'idéologie à celui de culture, qu'il prend dans son sens organisationnel et non politique en le décrivant comme «un système riche développé et profondément enraciné de valeurs et de croyances qui distingue une organisation particulière de toutes les autres » (MINTZBERG, 1989 : 320). Pour lui les idéologies organisationnelles recouvrent des structures plus conventionnelles, qu'on peut trouver dans les autres configuration de sa typologie, ainsi il oriente la discussion sur cette configuration sur ce qu'il considère être la force de l'organisation missionnaire, l'idéologie.

Il analyse le développement d'une idéologie organisationnelle en trois stades : le sens d'une mission, point d'ancrage de l'idéologie ; le développement de l'idéologie à travers les traditions et sagas, et ; le renforcement de l'idéologie par les processus d'identification. Le premier stade correspond à celui de la fondation d'une entreprise, qui peut être aussi une filiale. L'important c'est l'établissement d'une mission par un leader, autour duquel se réunissent un groupe d'individus. Ce regroupement peut aussi avoir un «sens de la mission», lorsque le sentiment du groupe est d'être réuni «pour former quelque chose de nouveau et de passionnant » (MINTZBERG, 1989 : 324).

Les raisons du phénomène de la création du «sens de la mission » sont : la latitude de manoeuvre qui offrent les nouvelles organisations; la possibilité qui offre la petite taille à l'établissement de relations personnelles, le partage des croyances et du désir d'ouvrer en commun et le charisme du leader.

C'est, d'après l'auteur le leadership charismatique qui peut permettre à des organisations déjà existantes la création d'une nouvelle idéologie, puisque les autres caractéristiques sont contraires à celles identifiées dans les entreprises qui sont en train de se fonder, comme l'existence de procédures, la grande taille, l'impersonnalité conséquente et l'existence d'un ensemble de croyances. Il paraît donc que Mintzberg lors qu'il parle d'idéologie et d'organisation missionnaire parle d'un type spécifique d'idéologie, qu'on peut approcher à ce que dans la littérature est appelé « la culture de la performance » ou qu'a été traité comme « la bonne culture ».

Le développement de l'idéologie est renforcé par les histoires qui se développent «autour des événements importants du passé de l'organisation ». L'ensemble des précédents, des habitudes et des mythes vont former « une base commune de traditions que les membres de l'organisation partagent et qui solidifient l'idéologie » (MINTZBERG, 1989: 325).

Le renforcement de l'idéologie est fait à travers l'identification des individus qui viennent intégrer l'organisation à cette ensemble de valeurs et croyances «qui pèsera lourdement sur [leur] comportement ». L'identification a plusieurs manières de se développer :

« - La façon la plus simple est l'identification qui se produit naturellement parce que le nouveau membre est attiré par le système de croyances de l'organisation. 
- l'identification peut également être sélective, les nouveaux membres sont choisis suivant leur adéquation au système de croyances existant, et les postes représentant l'autorité sont de la même façon attribués aux membres qui peuvent prouver une loyauté particulièrement forte et marquée à cet ensemble de croyances.

- L'identification peut aussi être suscitée. Lorsque le besoin de loyauté envers l'organisation est particulièrement grand, celle-ci peut avoir recours à des processus informels de socialisation et d'endoctrinement au moyen de programmes formalisés pour renforcer l'engagement naturel ou sélectif de ses membres à son système de croyances.

- Enfin, et sous son apparence la plus faible, l'identification peut être calculée. En effet, l'individu peut se conformer aux croyances de l'organisation non parce qu'il s'identifie naturellement avec celle-ci, ni parce qu'éventuellement elles lui conviennent, pas plus parce qu'il a subi une socialisation ou un endoctrinement dans cette optique mais simplement parce qu'il est payant pour lui de s'identifier avec ces croyances... » (Mintzberg, 1989 : 326-327, souligné dans le texte).

On voit à travers les manières par lesquelles l'identification peut se développer quelques-uns des principaux processus à travers lesquels le contrôle culturel est mis en œuvre: la sélection, la socialisation et l'endoctrinement. Nous allons les développer plus loin dans ce chapitre.

Pour Mintsberg l'identification lorsqu'elle est forte peut être utilisée comme un mécanisme de coordination, comme la supervision directe, la standardisation des procédés de travail, des résultats ou des qualifications sont utilisés dans les autres configurations. Ce mécanisme agit à travers la standardisation des normes que Mintzberg (1989 : 328)comprend comme « le partage d'un ensemble de valeurs et de croyances par tous ses membres ». C'est l'endoctrinement le paramètre de conception clef, au sens de :

«programme formalisé pour développer et renforcer l'identification des membres avec l'idéologie. Une fois que le nouveau membre a été sélectionné, socialisé et endoctriné il est accepté pour entrer dans le système comme un partenaire égal aux autres, capable de participer à la prise de décision comme n'importe quel autre membre de l'organisation. C'est ainsi, qu'à la limite, l'organisation missionnaire peut atteindre la forme la plus pure de décentralisation : tous ceux qui sont admis à entrer dans le système partagent son pouvoir » (Mintzberg, 1989 : 329).

Ce partage du pouvoir ne doit pas, néanmoins, être pris comme une absence de contrôle que pour l'auteur tend à être très puissant, même s'il est très subtile. Pour lui les contrôles, dans ce type d'organisation ne cherchent plus à se faire seulement sur le comportement des membres mais sur «leur âme même". Il explique : «L'organisation mécaniste achète ses ouvriers, ne tenant compte que du respect des règles qu'elle impose ; l'organisation missionnaire attire ses membres par leur 'cœur' »(MINTZBERG, 1989 : 329).

Mintzberg, met l'accent sur une autre possible source de tromperie, c'est-à-dire l'apparente souplesse de l'organisation missionnaire. Pour lui cette configuration ne se différencie pas fort de l'organisation mécaniste, puisqu'elle aussi repose sur une forme de standardisation, ce qui fait qu'elle soit aussi, fondamentalement bureaucratique. Si la standardisation des normes permet une structure plus fluide que les autres formes de standardisation, ces standards peuvent être fortement internalisés la transformant en une structure très rigide. Il dit (MINTZBERG, 1989: 330) :

« il faut conserver à l'esprit que les standards idéologiques tendent à être immuables : l'organisation missionnaire est plus incline à changer le monde qu'à se changer elle-même. En d'autres termes, elle est généralement trop occupée à interpréter 'la parole' pour mettre cette parole en question ».

La puissance de ce mécanisme de coordination fait disparaître les autres formes, selon l'auteur, chacun agissant en accord avec l'ensemble de croyances. La technostructure et la ligne hiérarchique, ainsi que la planification, le contrôle formalisé et les règlements formels sont fortement réduits. Les qualifications professionnelles peuvent aussi être découragées dans ce type d'organisation car elles évitent la possibilité de subir les contrôles normatifs des institutions qui forment les professionnels. Sur ce point Mintzberg (1989: 331) conclut : 
«... l'organisation missionnaire tend à être représentée par une masse amorphe, où les membres tirent 'tous ensemble' dans le sens de l'idéologie commune avec un minimum de spécialisation quant aux tâches, de différenciation dans ses parties, et de division dans ses statuts. A la limite, les managers, les spécialistes de fonctionnel, de support logistique et de technostructure et les opérateurs, une fois sélectionnés, socialisés et endoctrinés, finissent tous par se rassembler et peuvent en fait, occuper les différentes fonctions à tour de rôle».

\section{Tableau 3 - Comparaison organisation missionnaire et organisation bureaucratique}

\begin{tabular}{ll}
\hline Principes de l'organisation bureaucratique & Principes du Kibboutz \\
\hline 1. Poste permanent & Poste non permanent \\
\hline $\begin{array}{l}\text { 2. Le poste comporte des devoirs et des privilèges } \\
\text { définis et impersonnels. }\end{array}$ & $\begin{array}{l}\text { La définition du poste est floue : devoirs et privilèges ne } \\
\text { sont pas officiellement définis et dépendent souvent de } \\
\text { la personnalité du détenteur du poste. }\end{array}$ \\
\hline $\begin{array}{l}\text { 3. Une hiérarchie d'autorité fonctionnelle est exprimée } \\
\text { par l'autorité du détenteur du poste. }\end{array}$ & $\begin{array}{l}\text { Hypothèse de départ: toutes les fonctions sont } \\
\text { d'importance égale, absence d'une hiérarchie formelle } \\
\text { d'autorité. }\end{array}$ \\
\hline $\begin{array}{l}\text { 4. La nomination des détenteurs de postes intervient } \\
\text { d'après des qualifications objectives formelles. }\end{array}$ & $\begin{array}{l}\text { Les fonctionnaires sont élus et non pas nommés. Les } \\
\text { qualifications d'une manière objective ne sont pas } \\
\text { déterminantes, les qualités personnelles comptent plus } \\
\text { lors de l'élection. }\end{array}$ \\
\hline 5. Le poste est une occupation à plein temps. & $\begin{array}{l}\text { Le poste vient d'ordinaire s'ajouter à 1 'occupation à } \\
\text { plein temps du fonctionnaire. }\end{array}$ \\
\hline
\end{tabular}

Source : Mintzberg (1989:332)

En comparant l'organisation missionnaire, dans ce cas les Kibboutz traditionnels à l'organisation bureaucratique Mintzberg présente le suivant tableau, imaginé par Rosner .

L'auteur identifie trois types d'organisation missionnaires que sont des types extrêmes et qui ne peuvent pas s'appliquer directement au type d'organisation sous étude dans notre travail : les organisations réformatrices, les organisations de conversion et les cloîtres. Ces sont des types idéaux, dans le sens utilisé par Weber. Lorsqu'il parle d'entreprises qui présentent des caractéristiques proches de l'organisation missionnaire l'auteur se réfère aux études de Ouchi que nous avons déjà discuté.

\section{Les mécanismes du contrôle à travers la culture}

O'Reilly et Chatman (1996) approchent le thème de la culture par la difficulté d'un consensus entre les études, ce qui a générer un débat sur la définition de culture. Pour eux ce débat passe à côté d'une fonction critique de la culture dans les organisations qui est le contrôle social. Ils la définissent comme un système fondé sur le partage de valeurs et normes qui déterminent les expectatives sur les attitudes et comportements des membres. Elle est donc normative et opère à travers l'influence sociale et informationnelle. Ils définissent le contrôle dans une perspective psychologique sur la façon comme les individus le vivent . Le contrôle donc « comes from the knowledge that someone who matters to us is paying close attention to what we are doing and will tell us if our behavior is appropriate or inappropriate » (p. 161).

Les auteurs différencient le contrôle formel, codifié à travers des règles, des procédures et de la hiérarchie organisationnelle, du contrôle social, qui émerge dans la forme de valeurs et normes et qui est régulé à travers l'influence des pairs et de la construction social de la réalité. Ils le caractérisent comme étant plus extensif et moins cher que les systèmes formels résultant, néanmoins, en des sentiments positifs de solidarité et en un plus grand sens de l'autonomie. Ils expliquent ce paradoxe par l'internalisation de quelques valeurs organisationnelles telles que l'aide aux autres et la contribution pour la société. L'action de la culture comme un système de contrôle social se fait par l'augmentation de l'ouverture des membres à l'influence organisationnelle. Cette action peut inclure tant la décongélation des croyances antérieures que l'influence des croyances et comportements ultérieurs à travers les expectatives partagées et valorisées par les autres. 
O'Reilly et Chatman (1996) identifient quatre mécanismes utilisés par les organisations dites de culture forte pour générer engagement et gérer à travers le contrôle social. Le premier concerne les systèmes de participation qui amènent les personnes à se sentirent engagées. Ces systèmes font que les personnes se sentent personnellement responsables et donc engagées dans les travail. D'après les auteurs, Salancik (1977) propose quatre caractéristiques qui peuvent accentuer les effets de la participation : 1)volontariat (volitionality) ou choix ,2) publicité et visibilité, 3) explicitation, et 4) irrévocabilité. Afin de promouvoir l'engagement à travers la participation les entreprises développent de rigoureux processus de sélection et orientation ainsi qu'un "job design" que requiert de multiples étapes (O’Reilly et Chatman, 1996 : 175).

Le deuxième mécanisme se rapporte aux actions de managers que visent établir les buts à atteindre, déterminer la direction de l'attention et aider les personnes à interpréter les événements de façon à appuyer son importance intrinsèque. Ici les managers, à travers son propre comportement envoient des messages sur l'importance donnée à certaines attitudes et activités, c'est l'action symbolique du management . Les auteurs soulignent (p. 173) :

«although particular symbols by themselves are not likely to be effective, when they reflect an important and widely shared value they may shape interpretations and enhance the intrinsic importance attached to specific attitudes and behaviors... In this sense, managers who influences others'interpretations of events and see the intrinsec value of their efforts shape the social control system ».

Le troisième mécanisme fait référence aux informations reçues d'autres personnes valorisées par les membres de l'organisation. Ils font référence aux divers études de psychologie sociale sur l'influence du pouvoir informationnel. Dans le cas du contrôle social ce mécanisme agit à travers, notamment, l'influence des comportement des collègues de travail sur l'individu. Les exemples donnés par les auteurs sont les espaces de travail ouverts, l'informalité, les titres communs, l'inexistence de parkings réservés, les activités sociales, l'engagement de la famille.

Le quatrième mécanisme concerne un système de récompenses et reconnaissance compréhensible. Cela peut prendre la forme de petits cadeaux, reconnaissance par les pairs, vacances ou automobiles. O'Reilly et Chatman soulignent que les récompenses tangibles doivent être attribuées avec attention puisqu'elles peuvent réduire l'intérêt intrinsèque et la motivation quand initialement ils sont élevés. Ils soutiennent, avec Deci (1971) et Steele (1988) que le renforcement verbal et le feed-back positif agissent davantage sur la motivation que les récompenses externes, et aussi que les petites récompenses sont plus effectives que les grandes, surtout si elles sont encadrées comme appréciation plus que comme contrôle.

O'Reilly et Chatman (1996) font une comparaison entre les organisations de culture forte et les organisations religieuses que nous n'allons pas aborder ici car cela n'est pas la préoccupation centrale de notre étude. Néanmoins, dans leur conclusion, les auteurs soulignent quelques points liés au contrôle social qui nous semblent importants de discuter ici. D'abord, ils rappellent les différents résultats auxquelles on peut aboutir en utilisant la culture comme un contrôle social: l'augmentation de donations de sang, la conservation d'énergie, la promotion de l'innovation, du niveau des services offerts aux consommateurs, la qualité et le sens des objectifs communs dans les organisations. Mais on peut aussi aboutir à un comportement caractérisé par la déviance et l'exploitation personnelle et sociale ce que, d'après les auteurs, peut avoir lieu quand «les croyances sont intériorisées et la pensée critique est contrainte d'une telle façon que les individus sont induits à adopter un comportement contraire à l'éthique ou néfaste » (p.188) ${ }^{6}$. Ils citent les Schutztaffel dans l'Allemagne nazi, la distribution de ce qui est cru être des chocs fatals pour les personnes, en citant Milgram (1964) ou simplement ne pas percevoir les changements relevants de l'environnement compétitif qui conduit à la réduction de la performance organisationnelle. Donc le contrôle social par la culture peut être utilisé pour aboutir à des fins constructifs ou pernicieux.

\footnotetext{
${ }^{6}$ En anglais dans l'original.
} 
Ils donnent deux indices pour différencier les aspects fonctionnels et dysfonctionnels du contrôle social. Le premier concerne le contenu des normes et valeurs auxquelles les individus doivent s'identifier. Cela impose l'exposition honnête de ces normes et valeurs, pour que les membres sachent ce qu'on attend d'eux. Ce que permet aux individus de faire des choix bien informés sur les valeurs partagées par l'organisation et réduit les probabilités que les individus joignent involontairement des groupes qui violent leurs valeurs ou jugés contraires à l'éthique (p.188). Ils attirent l'attention sur l'importance de considérer certains processus organisationnels, notamment le contrôle formel. Ils disent :

«...formal control systems, which are often necessary and efficient, may fail to capture people's creativity and emotional commitment. Social control can engage people emotionally and provide them with direction and a sense of purpose. Whereas formal control systems tend to signal to employees that they are cogs in a machine and must conform to established rules and procedures, social control tends to convey a sense of autonomy and individual responsibility, likely precursors to creative thinking...» (p. 188).

Un deuxième indice se réfère à l'intensité du processus de contrôle social. Le défi ici serait de ne pas tomber dans la conformité demandée par les organisations religieuses, ce qu'empêche l'innovation et créé des résistances au changement. Une culture forte, dans les terme des auteurs, peut donc amener les individus à une excessive conformité faisant difficile l'expression du désaccord des membres ou la reconnaissance des inconsistances locales. L'organisation serait dirigée vers l'arrogance et l'inertie. Ils disent :

« Given the higher level of ideological and social investment members make, one wonders just how far they will stray from characteristic ways of doing things even when innovation is encouraged. That is, innovation may be encouraged in strong culture firms but stricter norms may exist to differentiate between new ideas characterized as innovative and those characterized as innapropriate due to a lack of alignement with the way things are currently done » (p. 191).

Pour eux le défi aux organisations c'est de maintenir un équilibre entre l'épanouissement des individus dans l'organisation et le contrôle des pensées et des actions ; Néanmoins la critique d'Enriquez (1989) sur les organisations stratégiques montre, d'une certaine façon, l'impossibilité de cet équilibre

Van Maanen et Kunda (1989) développent dans leur travail l'argument que les règles qui gouvernent l'expression émotionnelle sont liées à la compréhension culturelle des membres et dictent le comportement appropriés dans le lieu de travail. Leur analyse est basée sur deux études ethnographiques qui « détaillent la façon par laquelle la vie organisationnelle est structurée pour canaliser, modeler, renforcer, soutenir, challenger, et autrement influencer les sentiments ou les membres organisationnels - à travers l'organisation elle-même, d'autres dans l'organisation, les clients de l'organisation, et, fondamentalement, eux-mêmes » (p.58). Ses études ont été réalisées à Disneyland et dans une entreprise de haute technologie à laquelle ils ont donné le pseudonyme de High Technology Incorporated, plus spécifiquement dans une division d'ingénierie, considéré comme le cœur de l'entreprise.

Dans leur conclusion les auteurs répondent à la question comment les managers de organisations influencent la culture autour des employés clé et d'eux-mêmes. En premier lieu les auteurs placent la codification des valeurs et croyances comme un moyen important de promouvoir une sorte de conscience culturelle entre les membres de l'organisation. Cela concerne les histoires racontées dans l'entreprise, les exemples d'employés hautement performants devenus publiques.

Un deuxième point fait référence à la promotion d'une interaction considérable et de forts liens entre les employés. Cela peut comprendre les événements sociaux, les fêtes, les cérémonies officiels, ainsi que l'arrange physique des espaces de travail et le travail en groupe. Ces mécanismes évitent les actions de auto-estime (selfregarding) puisque les intérêts des participants des groupes sont interdépendants. Le comportement des membres est donc contrôlé par les autres, cela sert aussi, au fur et à mesure que l'individu connaît le processus de contrôle par les membres, à conduire l'individu vers l'auto-contrôle. 
En troisième lieu, les auteurs soulignent la grande attention faite aux nouveaux venus dans cet « enclave culturel ». En fait, pendant leur analyse Van Maanen et Kunda (1989) montrent la grande préoccupation des deux organisations par rapport au processus de sélection. Chez Disneyland les exigences physiques sont largement connues. Le processus de socialisation prend, lui aussi, une autre dimension. Il est intensif à l'entrée de l'individu recruté mais il est constamment renforcé au long de la vie au travail. Les auteurs résument :

«Homogenenity of recruit backgrounds, intensive peer socialization, continuous exposure to the apparently always risky business of creating and maintainning acceptable, if not harmonious, relations with colleagues and supervisors, tales of corporate heroism (and cowardice), and numerous occasions (mundane and dramatic) to test one's standing in the group are key elements contributing to the maintenance and support of the culture » (p. 87).

En ce qui concerne la sélection et la socialisation dans les organisations qu'utilisent les mécanismes du contrôle à travers la culture, Ouchi (1979) présente une analyse qu'il faut prendre en compte. L'auteur souligne que dans une organisation du type Clan, le système d'information ne peut pas faire face à l'hétérogénéité ni au turnover, ce qui pose des difficultés pour les organisations modernes d'utiliser le contrôle par le clan comme le mécanisme central de contrôle (p. 840). L'auteur présente aussi une classification de ces trois modes de contrôle, le marché, la bureaucratie et le clan, par rapport au traitement des personnes et à la forme d'engagement. A un extrême l'organisation est non sélective et prend n'importe qui. Ouchi (1979: 841) souligne qu'on doit assumer que ces personnes ont des intérêts propres et qu'elles cherchent à maximiser les gains. Ces valeurs internalisés de recherche de la maximisation des gains permet l'utilisation du mécanisme du marché où les objectifs de l'organisation et des individus sont identiques et donc on peut se passer de la supervision. Dans l'autre extrême, l'organisation est hautement sélective et cherche à n'embaucher que des individus possédant déjà les valeurs et les habilités qu'elle nécessite. Cette pratique peut être observée dans des organisations qu'on appelle bureaucraties professionnelles, comme les hôpitaux et les universités. Nous avons déjà abordé ce type d'organisation et de mécanisme de contrôle quand nous avons parlé du contrôle professionnel, dans la première partie de ce chapitre. Dans ce cas les individus ont passé, avant d'entrer dans l'organisation par une longue période de formation que les permet d'acquérir les habilités et les valeurs (partagées par la profession) que l'organisation cherche. Ces deux types d'organisation montrent un haut niveau d'engagement puisque les valeurs sont internalisées.

Ouchi (1979 : 842) souligne que la plupart des organisations ne peuvent pas utiliser ces deux mécanismes et qu'elles utiliserons, donc, les processus de formation pour transmettre les valeurs désirées et ainsi alléger les coûts et les conséquences d'un contrôle important qui offenserait le sens d'autonomie et d'auto-contrôle, donnant lieu à un comportement sans enthousiasme qui demanderait encore plus de contrôle. Sur ce point Ouchi (1979: 841), dit :

«... as is always true of any form of measurement, it is not possible for an organisation to measure or otherwise control its employees without somehow affecting them through the very process that it uses to measure them : there is no completely unobstrusive measurement in most organizations. In general, the more obvious ans explicit the measurement, the more noxious it is to employees and thus, the greater the cost to the organization of employing such methods... »

La liaison entre les types de contrôle et la forme d'engagement est directe chez Ouchi. La bureaucratie, quoique elle puisse utiliser l'identification, ne nécessite que de l'observation (compliance). C'est qui est fondamental pour le contrôle bureaucratique est la suspension du jugement devant les ordres des supérieurs hiérarchiques, les subordonnés devant simplement les suivre (OUCHI, 1979 ; BLAU ET SCOTT, 1962). Pour le mécanisme de contrôle du marché la forme d'engagement est l'internalisation puisqu'il ne possède pas de surveillance hiérarchique. Le clan peut être supporté par l'identification, mais avec le temps l'identification se convertira en internalisation des valeurs du clan.

Ouchi attire l'attention sur la façon par laquelle les organisations qui ne peuvent pas embaucher des personnes, portant exactement les valeurs dont elle a besoin, agissent pour que les individus poursuivent les objectifs organisationnelles. Elles vont compter sur la formation, soit sur la base de programmes formels soit sur la 
forme de « on-the-job » ou formation d'apprenties pour transmettre les valeurs. D'après Ouchi (1979: 842) les employés vont s'identifier avec le formateur, qui peut être un supérieur hiérarchique et c'est cette identification qui va leur faire poursuivre les objectifs de l'organisation. Pour lui ce n'est pas l'internalisation des valeurs qui fait croire aux individus le caractère souhaitable de ces objectifs. Dans le clan, l'internalisation viendra plus tard.

Van Maanen et Kunda (1989), évoquent, finalement, l'attention et l'effort fait dans le sens de surveiller l'étendue des valeurs, normes et pratiques organisationnelles. Chez Disneyland les managers montrent un style pénétrant qui considère la vie personnelle des membres. Chez Tech le sens est inversé et ce sont les subordonnés qui s'intéressent à la façon de penser et aux sentiments des managers. Les auteurs soulignent la caractéristique de franchise montrée par les deux organisations, c'est-à-dire, les individus sont encouragés à dire ce qu'ils pensent et sentent de façon nette, franche et fréquemment rude.

Les mécanismes du contrôle par la culture présentés par O'Reilly et Chatman (1996) et Van Maanen et Kunda (1989), nous semblent assez proches et ne montrent que quelques différences qui ne s'opposent pas et sont complémentaires. Le tableau ci-dessous résume les caractéristiques du contrôle à travers la culture, présentées par chacun des travaux que nous venons discuter.

Dans ces schémas, le système de participation et la promotion de l'interaction entre les employés, nous semblent faire référence aux mêmes processus. Les entreprises qui utilisent davantage la culture comme un contrôle auront tendance à promouvoir divers dispositifs de participation. Le travail organisé en cellules, les groupes de CCQ (Cercle de Contrôle de Qualité) et GSP (Groupe de Solution de Problèmes), les fêtes, les cérémonies (la récompense des meilleures) sont des exemples de ces dispositifs.

Néanmoins, O'Reilly et Chatman incluent dans le système de participation le processus de sélection, alors que Van Maanen et Kunda le voient comme un mécanisme particulier. Vu l'importance que ce processus prend dans les organisations qui utilisent le contrôle par la culture, il nous semble plus approprié de le considérer comme un mécanisme de ce type de contrôle.

La codification des valeurs et croyances et l'action symbolique des managers peuvent être assimilés. D'abord parce que ce sont les managers qui essayent de codifier les valeurs et croyances que l'organisation va promouvoir. Bien entendu, ils ne sont pas les seuls à le faire, puisque les employés, eux aussi, racontent des histoires et, parlent de héros qui ne correspondent pas forcement aux valeurs et croyances codifiées par le management. Ensuite, parce que dans ces organisations, la formation est de plus en plus assurée par les managers qui essayent donc de collectiviser leurs interprétations des événements. 
Tableau 4 - Comparaison des mécanismes du contrôle dans deux auteurs

\begin{tabular}{ll}
$\begin{array}{l}\text { Influence des managers sur la culture } \\
\text { (Van Maanen et Kunda) }\end{array}$ & $\begin{array}{l}\text { Mécanismes du contrôle social par la culture } \\
\text { (O'Reilly et Chatman) }\end{array}$ \\
\hline $\begin{array}{l}\text { Codification des valeurs et croyances } \\
\text { - histoires }\end{array}$ & $\begin{array}{c}\text { Systèmes de participation } \\
\text { - sélection } \\
\text { - héros }\end{array}$ \\
- formation & - travail en groupe \\
\hline Promotion de l'interaction des employés & Action symbolique des managers \\
- fêtes & - interprétation \\
- cérémonies & - exemples \\
- travail en groupe, etc. & \\
\hline Attention donné au processus de sélection & Information des collègues \\
- homogénéité des recrutés & - distinctions hiérarchiques réduites \\
- socialisation intensive et extensive & - activités sociales et participation des \\
- relations harmonieuses & familles \\
& - espace communs de travail \\
\hline Surveillance des valeurs & Système de récompenses et reconnaissance \\
- attention à la vie personnel des employés & - feed-back positif \\
- attention aux pensées des collègues, & - cadeaux \\
supérieurs hiérarchiques et subordonnés. & - promotion \\
\hline
\end{tabular}

\section{En guise de conclusion}

La discussion des mécanismes de contrôle que nous avons proposé ne englobe pas, évidement, toute la richesse que porte ce sujet. Il nous semble, néanmoins, que la compréhension des transformations du contrôle, vu sa centralité pour les études organisationnelles, serait enrichi par un approche visant éclaircir les categories liés aux nouvelles formes de controle, notamment ce que nous avons appelé le contrôle à travers la culture.

Dans ce que la littérature consultée met en relief nous pouvons conclure que les principaux mécanismes sont liés aux processus de sélection (homogénéité des récrutés, socialisation intensive et extensive et relations harmonieuses), au sistème de participation (travail en groupe, fêtes e cérémonies), à la codification des valeurs et croyances (histoires, formation, interprétation, distinction hiérarchiques réduites), à la surveillance des valeurs (attention à la vie personneles des individus, attention aux pensées des collègues) et, au système de récompenses et reconnaissance (feed-back positif, cadeaux, promotion). Cette construction pourrait être beaucoup enrichi avec une comparaison plus détaillée entre les mécanismes des différents modes de contrôle, limitée dans ce travail par l'espace que nous est proporcionné. 


\section{Bibliographie}

AMADO, G. Cohésion organisationnelle et illusion collective. Revue Française de Gestion, juin-juillet-août, pp. 37- 43,1988.

AMBLARD, H. et al. Les nouvelles approches sociologiques des organisations. Paris: Seuil, 1996.

ANTHONY, R.N. The management of control function. Boston, Massachussets: The Harvard Business School Press, 1988.

AUBERT, N. GAULEJAC, V. De a logique du "donnant-donnant" à l'exigence du "toujours plus" : le système managinaire. Connexions, $n^{\circ}$. 54, pp. 127-144, 1989.

BERNOUX, P. La sociologie des organisations. Paris: Seuil, 1985.

BLAU, P. et SCOTT, R. Formal Organization. San Francisco : Scott, Foreman, 1962.

BOUCHIN, H. Le contrôle de gestion - contrôle de gestion, contrôle d'entreprise. Paris : PUF, 1988.

BRAVERMAN, H. L'organisation scientifique du travail. In : Chanlat, J.F. et Seguin, F. L'analyse des organisations, Tome 1, "Les théories de I'organisation'. Quebec : Gaëtan M orin, 1983.

CARVALHO, C. Poder, conflito e controle nas organizações modernas. Maceió: EDUFAL, 1998.

CHIAPELLO, E. Les typologies des modes de contrôle et leurs facteurs de contingence : un essai d'organisation de la littérature. Comptabilité-Contrôle-Audit. Tome 2, Vol. 2, septembre, 1996.

CHIAPELO, E. Les tipologies des modes de contrôle et leurs facteurs de contingence: un essai d'organisation de la littérature. Comptabilité-Contrôle-Audit. Tome 2, v. 2, septembre, 1994.

CHILD, J. (). Organization structure and strategies of control. Administrative Science Quarterly, vol. 17, pp.163-177, 1972.

CHILD, J. (1984). Organization. A guide to problems and practice. London : Paul Chapman publishing Ltd.

CLEGG, S. (1987). Organisation et Contrôle du Procès de Travail. In : Chanlat et Seguin. L'analyse des Organisations - une anthologie sociologique. Tome II. Quebec : Gaëtan Morin.

CROZIER, M. e FRIEDBERG, E. (1977). L'acteur et le système. Paris: Seuil.

DECl, E.L. (1971). Effects of externally mediated rewards on intrinsic motivation. Journal of Personality and Social Psychology, Vol. 18, $n^{\circ}$. 1, pp. 105- 115.

DELEUZE, G. (1990). Pourparlers. Paris : Les Editions de Minuit.

DERMER, J. (1988). Control and organizational order. Accounting, Organizations and Society, v. 13, n. 1, pp. 25-36.

EDWARDS, R.C. (1981). The social relations of production at the point of production. In : Zey-Ferrel, M. et Aiken, M. (eds.). Complex organizations : critical perspectives. Glenview, IL : Scott, Foresman, pp. 156-182.

ENRIQUEZ, E. (1989). L'individu pris au piège de la structure stratégique. Connexions, n. 54, pp. 145-161.

ETZIONI, A. (1965). Organizational control structure. In: March, J. (ed.) Handbook of organizations. Chicago: Rand Mcnally and Company. HICKSON, D. J., HINNING, C. R., Lee, C. A., SCHNECK, R. E. et PENNINGS, J. M. et al. ( 1971). A strategic contingencies theory of intraorganizational power. Administrative Science Quarterly, 16 : 216-229.

HICKSON, D. J., PUGH, C. R., PHEYSEY, D. C. ( 1969). Operation technology and organization structure: na empirical reappraisal. Administrative Science Quarterly, 14: 378-397.

HINNINGS, C.R. et LEE, G.L. (1971). Dimensions of organization structure and their context : a replication. Sociology, vol. 5, pp. 83-93.

KALIKA, M. (1995) Structures d'Entreprise. Paris : Economica.

KHANDWALLA, P.N. (1976).Organizational design for change. Learning Systems, Conceptual Readings 5.

LEBAS, M. (1980). Toward a theory of management control: organizational process, information economics, and behavioral approaches. Cahier de Recherche n. 158. HEC-ISA.

MINTZBERG, H. (1982). Structure et dynamique des organisations. Paris : Les Editions d'Organisation.

M INTZBERG, H. (1990a). Le management. voyage au centre des organisations. Paris : Editions d'organisation.

O'REILLY, C ; et CHATMAN, J. (1996). Culture as social control : corporations, cults, and commitment. Research in Organizational Behavior, vol. 18, pp. 157-200.

OUCHI, W. (1977). The relationship between Organizational Structure and Organizational Control. Administrative Science Quarterly, vol. 22, March.

OUCHI, W. (1979). A conceptual framework for the design of Organizational Control Mechanisms. Management Science. Vol. 25, $n^{\circ} 9$, September. 
OUCHI, W. (1980). Markets, Bureaucraties and Clans. Administrative Science Quarterly. Vol. 25, March.

OUCHI, W. (1982). Théorie Z - faire face au défi japonais. Paris : InterEditions.

OUCHI, W. et Johnson, J. (1978). Types of Organizational Control and tehir relationship to emotional Well Being. Administrative Science Quarterly, vol. 23, June.

OUCHI, W. et Maguire, M. (1975). Organizational Control : two functions. Administrative Science Quarterly. Vol. 20, December.

SIMON, H. (1945). Administrative Behavior. New York : Free Press.

SOLÉ, A. (1996). La décision: production de possibles et d'impossibles. In: Traité d’ergonomie. Ouvrage collectif. Paris: Editions Octares Entreprises.

STEELE, C. (1988). The psychology of self-affirmation : sustaining the integrity of the self. In : BERKOWITZ, L. (Ed.), Advances in experimental social psychology, Vol. 21, New York Academic Press.

TANNENBAUM , A.S. (1968). Control in organizations. New York: Mcgraw Hill.

VAN MAANEN, J. et KUNDA, G. (1989). Real feelings: Emotional expression and organizational culture. In : Staw, B. et Cummings, L. (eds.), Research in Organizational Behavior. Vol. 11, pp. 43- 103.

WEBER, M. (1991). Economia e Sociedade. Tome 1. Brasília : UNB Editora. 